\title{
USOS DE AGROTÓXICOS NAS AGROPECUÁRIAS DO BRASIL, ESTADOS UNIDOS E UNIÃO EUROPEIA
}

\author{
Comparison Among Brazil, the United States and European Union Countries About \\ Pesticides Use in their Agricultures
}

\begin{abstract}
RESUMO
Desde 1990, o Brasil vem aumentando significativamente o consumo de agrotóxicos, já ultrapassando em 2009 o consumo absoluto da União Europeia por esses produtos e desde 2008 o consumo por hectare de lavoura nos EUA. Na segunda década do século XXI, há evidência gráfica de que o consumo de agrotóxicos por hectare de lavoura está se estabilizando, ainda que em patamares distintos, nessas três regiões. Adicionalmente, observa-se, em termos gráficos, simultaneidade do crescimento do uso de agrotóxicos no Brasil e o crescimento da produtividade das lavouras neste país. Diante deste contexto, o objetivo do estudo foi analisar, em termos econométricos, o comportamento do consumo de agrotóxicos nestas três regiões e, especificamente para o Brasil, a relação entre o consumo de agrotóxicos e a produtividade agrícola brasileira, considerando os anos de 1990 a 2016 . As análises de cointegração de Johansen indicam ocorrer relações de longo prazo entre os consumos de agrotóxicos por hectare de lavouras entre o Brasil, EUA e União Europeia, bem como entre esse consumo de agrotóxicos e a produtividade das lavouras no Brasil. Quanto a essa última relação, as estimativas do modelo SVEC mostram, de modo geral, uma relação direta entre essas duas variáveis no caso brasileiro.
\end{abstract}

Cristiane Mitie Ogino

Universidade de São Paulo

cristianeogino@gmail.com

Carlos José Caetano Bacha

Universidade de São Paulo

carlosbacha@usp.br

Recebido em: 19/08/2020. Aprovado em: 14/05/2021.

Avaliado pelo sistema double blind review

Avaliador científico: Eduardo Cesar Silva

DOI: $10.48142 / 2320211687$

\begin{abstract}
Since the year of 1990, Brazil has significantly increased its consumption of pesticides, already overcoming in 2009 the total pesticide consumption of the European Union countries and since the year of 2008 the US agriculture consumption of pesticide per hectare of crop. In the second decade of the 21 st Century, there is a graphic evidence that the consumption of pesticides per hectare of crop is stabilizing, albeit at different levels, in these three regions. When plotting in the same graph agricultural productivity and consumption of pesticides in Brazil, a high correlation between these two variables shows up. Given this context, the objective of the study was to analyze, in econometric terms, the behavior of pesticide consumption in these three regions and, specifically for Brazil, the relationship between pesticide consumption and the Brazilian agricultural productivity, taking into consideration the years ranging from 1990 thru 2016. Johansen's Cointegration analyzes also supports that a long-term relationship takes place among pesticide use in Brazil, USA and EU countries as well as between productivity growth and pesticide use in Brazil. Additionally, a SVEC model was run to show up the relation between pesticide use and agricultural productivity in Brazil, unveiling a direct relationship between them.
\end{abstract}

Palavras-chaves: Teste de Cointegração; SVEC; Consumo; Agricultura.

Keywords: Cointegration Test; SVEC; Consumption; Agriculture.

\section{INTRODUÇÃO}

Os agrotóxicos, termo utilizado pela legislação brasileira, ou também conhecidos como pesticidas agrícolas, agroquímicos, defensivos agrícolas ou produtos fitossanitários são definidos como sendo:

... os produtos e os agentes de processos físicos, químicos ou biológicos, destinados ao uso nos setores de produção, no armazenamento e beneficiamento de produtos agrícolas, nas pastagens, na proteção de florestas, nativas ou implantadas, e de outros ecossistemas e também de ambientes urbanos, hídricos e industriais, cuja finalidade seja alterar a composição da flora ou da fauna, a fim de preservá-las da ação danosa de seres vivos considerados nocivos (Brasil, 2012, p.1).

Tais produtos têm demonstrado ser insumos que se associam ao aumento da produtividade agrícola, por 
atuarem na redução das perdas causadas pelas pragas e doenças que atacam as plantas (Lopes \& Albuquerque, 2018).

Mesmo sabendo que o uso inadequado dos agrotóxicos causa malefícios ambientais e à saúde humana, as justificativas para a sua utilização são que os benefícios à manutenção da produtividade agrícola superam os custos e as externalidades negativas causadas pelos agrotóxicos (Atreya et al., 2011).

No presente momento, o Brasil é um dos países que mais utilizam agrotóxicos no mundo, destacando o uso crescente desse produto a partir da década de 1970. A partir dos anos 1990, mesmo com vários momentos de taxa de juros reais elevadas, o uso dos agrotóxicos foi estimulado pela redução relativa dos preços desses insumos agrícolas, sendo que essa redução de preços relativos foi advinda da valorização cambial e da liberação comercial vivenciada pela economia brasileira. Junto a esse maior uso de agrotóxicos houve o aumento da produção e das exportações dos produtos agrícolas (Carvalho \& Silva, 2008).

Entre 1990 e 2010, o consumo anual de agrotóxicos no Brasil passou de aproximadamente 50 mil toneladas para 300 mil toneladas de ingredientes ativos, isto é, aumentou em seis vezes. Este é um cenário diferente do ocorrido nos Estados Unidos e nos países da União Europeia, que no mesmo período não tiveram tendência de crescimento no consumo desses produtos. Nos EUA, em idêntico período, o consumo de agrotóxicos ficou, na média anual, entre 350 mil e 450 mil toneladas; enquanto o mesmo consumo anual na União Europeia ficou entre 300 mil e 400 mil toneladas de ingredientes ativos, segundo dados da Organização das Nações Unidas para Agricultura e Alimentação (FAOSTAT, 2018). Em 2009, o Brasil ultrapassou pela primeira vez o consumo da União Europeia de agrotóxicos, ficando um pouco abaixo do consumo dos Estados Unidos.

Esse aumento do consumo de agrotóxicos no Brasil, junto com outros insumos, possibilitou com que a produtividade agrícola crescesse. A produtividade média das 38 principais culturas conduzidas no Brasil passou de $7.618 \mathrm{~kg} / \mathrm{ha}$ em 1990 para mais de 13.864 kg/ha em 2016 (ver Apêndice).

Autilização dos diferentes agrotóxicos dependerá das normas vigentes em determinado país. No Brasil, o controle do uso dos agrotóxicos é realizado, simultaneamente, por três órgãos: o Ministério da Agricultura, Pecuária e Abastecimento (MAPA), a Agência Nacional de Vigilância Sanitária (ANVISA) e pelo Instituto Brasileiro do Meio Ambiente e dos Recursos Naturais Renováveis (IBAMA), que estabelecem as diretrizes para o uso dos agrotóxicos (BRASIL, 2012). Já nos Estados Unidos, o órgão que controla o uso de agrotóxicos é a Agência de Proteção Ambiental (EPA), a qual fica também responsável pela supervisão do cumprimento das leis federais relacionadas ao uso de agrotóxicos. E, na União Europeia, o procedimento para adotar um ingrediente ativo nas lavouras é determinado em conjunto pelos países do bloco, sendo o órgão regulamentador a Agência Europeia dos Produtos Químicos (ECHA), a qual é vinculada à Autoridade Europeia de Segurança Alimentar (EFSA). Isso faz com que ocorram certas diferenças quanto ao emprego dos agrotóxicos, sobretudo, sobre quais os ingredientes ativos são permitidos para utilização entre os países (Schreinemachers \& Tipraqsa, 2012).

Não obstante a diferença de legislação entre os países grandes consumidores de agrotóxicos, os pacotes tecnológicos utilizados pelos mesmos tornam imprescindíveis o uso de agrotóxicos nas produções agrícolas em grandes escalas. Isto sugere haver alguma relação de longo prazo entre os consumos desses países por agrotóxicos à medida em que eles se tornam grandes produtores de produtos agrícolas. E, como dito no início deste item, os ganhos de produtividade (em termos de produtividade da terra) se associam com o uso de insumos, tais como os agrotóxicos.

O objetivo geral deste artigo é analisar, no período de 1990 a 2016, a possível existência de relação de longo -prazo (a apresentação de um caminhamento comum) entre o Brasil, os Estados Unidos e a União Europeia quanto ao uso de agrotóxicos e evidenciar a relação entre a evolução da produtividade agrícola e o consumo de agrotóxicos no Brasil.

Especificamente para o caso do Brasil, o artigo tem como objetivos específicos:

(1) Identificar a presença de equilíbrio de longo-prazo entre o consumo de agrotóxicos por área plantada no Brasil e a sua produtividade. Embora essa relação seja bastante evidente quando plotadas ambas variáveis em um gráfico, procurar-se-á confirmá-la com o emprego do teste de cointegração de Johansen (Johansen, 1988). (2) A partir da relação entre o consumo de agrotóxicos por área plantada no Brasil e a sua produtividade, estimar as trajetórias dessas variáveis quando aplicado um choque não antecipado em cada uma delas, por meio da função impulso-resposta. Isto permitirá ressaltar a relação entre essas duas variáveis.

Os resultados a serem obtidos pelo artigo são no sentido de evidenciar, econometricamente, se o Brasil está em um caminho (trajetória) similar ou diferente de outros países mais desenvolvidos no uso de agrotóxicos e também destacar a importância desses produtos na busca de manutenção ou aumento de produtividade.

Este artigo compõe-se de mais quatro seções além desta Introdução. A seção 2 apresenta a revisão da literatura mais próxima aos objetivos supra delimitados e situa a contribuição do 
artigo neste conhecimento. Aseção 3 apresenta a metodologia e os dados utilizados para atingir os objetivos do artigo. A seção 4 apresenta os resultados empíricos do trabalho e é sucedida pela seção 5, a qual traz as considerações finais do artigo.

\section{REVISÃO DE LITERATURA}

As formulações dos agrotóxicos têm como base os ingredientes ativos, isto é, os componentes principais do produto, cuja função é restringir a ação do agente a ser controlado -por exemplo, o crescimento de plantas daninhas à cultura, de insetos ou vírus que atacam suas folhas (BRASIL, 2012). Esses ingredientes ativos, na divisão mais ampla, distinguem os agrotóxicos conforme as classes de uso, sendo que os mais empregados no mundo são os herbicidas, os fungicidas e os inseticidas, isto é, para controle de plantas daninhas, doenças fúngicas e insetos e outras pragas, respectivamente (FAOSTAT, 2018).

Há muitos princípios ativos existentes no mercado, com variadas potencialidades de eficácia no controle de pragas e doenças, assim como variações de grau de toxicidade, as quais dão origem a classificações conforme a sua periculosidade ao ambiente e aos seres vivos. Essa periculosidade dos agrotóxicos leva os países a adotarem medidas distintas de regulamentação, mas sempre visando evitar o seu mau uso.

Williams \& Shumway (2000) mostraram que os países mais desenvolvidos, como os Estados Unidos e alguns que compõem a União Europeia, têm maior capacidade de uso correto de agrotóxicos, dados o seu nível de educacional e de renda, o que facilita o emprego de insumos intensivos em capital. Ademais, segundo Curzi et al. (2018), os países da União Europeia se caracterizam por estabelecerem padrões relativamente mais rigorosos quanto ao uso de agrotóxicos.

Böcker \& Finger (2016) constataram que a demanda por agrotóxicos nos Estados Unidos e na União Europeia é inelástica a variações de preços, com mediana desta elasticidade sendo de -0,28. Esses autores observaram também que a demanda de agrotóxicos para uso em pastagens possui maior elasticidade-preço do que para o uso de agrotóxicos em culturas, tais como as plantações de frutas e hortaliças. Essas últimas possuem o produto colhido com maior valor de mercado, além da alta exigência do aspecto qualitativo, o que implica maior frequência de aplicações preventivas de agrotóxicos. Já em relação ao tipo de agrotóxicos, os mesmos autores encontraram que a demanda por herbicidas apresentou maior elasticidade-preço da demanda do que a de outros defensivos químicos, como fungicidas e inseticidas.

Schreinemachers \& Tipraqsa (2012) analisaram o uso dos agrotóxicos de acordo com a renda dos países. Os autores concluem que quanto mais alto é o nível renda de um país, menor é o crescimento do seu consumo de agrotóxicos, apesar de esses países de alta renda não conseguirem reduzir o nível de uso desses produtos. Em contrapartida, país de renda média ou baixa revela crescimento rápido do uso de agrotóxicos. As diferenças de intensidade de consumo de agrotóxicos entre os países estão relacionadas com a atividade econômica prevalecente no seu território. Geralmente, nos países de média e baixa renda o uso da terra é fortemente vinculado à atividade agrícola.

A falta de alternativas mais baratas para controle de doenças e pragas em grandes áreas plantadas com a mesma cultura é particularmente mais preocupante em regiões com clima tropical, como no caso do Brasil, haja visto que o clima tropical propicia o cultivo escalonado e contínuo na mesma área, aumentando o tempo de uso do solo no ano, graças à ausência de inverno rigoroso (ECOBICHON, 2001). Em contrapartida, essa mesma possibilidade, ao permitir com que a atividade agropecuária esteja sempre ativa ao longo do ano, resulta na não quebra de ciclo das pragas e doenças por meio físico natural. Isto faz com que os agricultores brasileiros busquem soluções para o combate às enfermidades, e entre essas soluções o uso dos agrotóxicos está entre as mais empregadas.

No Brasil, o uso crescente dos agrotóxicos foi estimulado através de políticas direcionadas à modernização da agropecuária. Dentre essas políticas se destacam a de crédito e a de extensão rural, as quais incentivam a aquisição pelos agricultores de insumos modernos, tais como os agrotóxicos, os fertilizantes, as máquinas e implementos agrícolas de alto desempenho (Souza \& Lima, 2003). Nos anos 2000, o Brasil passou a ser um dos países maiores consumidores de agrotóxicos, sendo que em 2010 o mercado brasileiro desses produtos movimentou cerca de US $\$ 7,3$ bilhões, equivalente a 19\% do mercado global de agrotóxicos (Carneiro et al., 2015).

Pedlowski et al. (2012) ressaltam que apesar do aumento do consumo de agrotóxicos propiciar aumento de produtividade na agricultura do Brasil, há sérios problemas quanto ao uso correto e seguro desses produtos. Entre esses problemas estão os relacionados ao emprego inadequado de equipamentos de proteção individual, mistura de produtos que aumentam o risco de contaminação do ecossistema e o uso de mão de obra não qualificada para tal, em função do seu limitado nível educacional. Essa última variável também faz com que a eficácia da aplicação do produto químico seja comprometida, caso as recomendações de aplicação não sejam seguidas.

Diversos estudos discutiram meios de como reduzir o uso de agrotóxicos. Dasgupta et al. (2002) expõem que regulamentos mais rigorosos não contribuem para a 
diminuição do consumo desses produtos. Em muitos países não há recursos necessários para esse controle. Um modo mais eficiente de controle do uso de agrotóxicos é a redução de subsídios à compra dos mesmos, programas de extensão rural para a instrução da utilização correta desses insumos e o ensino de outros métodos de controle de pragas e doenças. Considera-se, também, a imposição de tarifas mais altas sobre os agrotóxicos importados.

Alternativamente ao uso dos agrotóxicos, há outros meios de controle de pragas e de doenças na agricultura, tais como: métodos culturais, mecânicos, físicos, controle biológico e o manejo integrado (Gallo et al., 2002). No entanto, a adoção desses métodos é mais complexa quando comparada ao uso de agrotóxicos, por exigirem maior conhecimento do funcionamento do sistema cultural para concretizar o controle das enfermidades.

Não obstante a existência de métodos alternativos de controle de pragas e doenças em relação ao uso de agrotóxicos, esses últimos acabam sendo muito utilizados em plantios homogêneos e em grande escala, como no Brasil, nos EUA e nos países da União Europeia.

\section{METODOLOGIA}

Os modelos econométricos que tratam de séries temporais, para serem ajustados e evitarem a estimação de relações espúrias, necessitam que as séries das variáveis sejam submetidas, em um primeiro momento, a um teste de presença de raiz unitária, com o propósito de constatar possíveis presenças de tendência estocástica e determinar a ordem de integração da série (ENDERS, 2010). Para tanto, neste artigo foram empregados o teste de Dickey e Pantula (1987) e o teste DF-GLS (1996) sobre as variáveis, consideradas em seus logaritmos, que aparecem no Quadro 1.

O teste de Dickey e Pantula (1987) testa a presença de duas raízes unitárias, número máximo de raízes presentes na maioria das séries (ENDERS, 2010). Caso a série (mostrada na primeira coluna do Quadro 1) resultar na não significância estatística de existência de 2 raízes unitárias, aplica-se, também, o teste DF-GLS. Esse teste - proposto por Elliott, Rothenberg e Stock (1996) - foi desenvolvido a partir da alteração do teste Dickey-Fuller Aumentado (teste ADF) e é empregado para testar a presença de apenas 1 raiz unitária.

Se os resultados dos testes indicarem que as séries sejam não estacionárias e apresentem a mesma ordem de integração, é necessário analisar se as variáveis são cointegradas entre si.

O conceito de cointegração foi introduzido por Engle \& Granger em 1987, e refere-se à análise de relações de longo-prazo entre as variáveis. Para saber se as variáveis são relacionadas (apresentam um caminhamento comum), utilizou-se o teste de cointegração de Johansen, que consiste em uma combinação linear entre as variáveis. Quando essa combinação linear entre as variáveis for igual a zero, diz-se que o sistema se apresenta em equilíbrio de longo-prazo (Enders, 2010).

O teste de cointegração de Johansen é realizado ao se utilizar uma matriz de integração com diferentes termos determinísticos. A inclusão desses termos determinísticos dependerá da performance do modelo. E para a presente análise estatística utilizou-se a estatística $\lambda$-traço, elaborada por Johansen (1988).

QUADRO 1 - Descrição das variáveis utilizadas no estudo

\begin{tabular}{|c|c|c|c|}
\hline Variável & Descrição & Período & Fonte \\
\hline lagrotx_BR & $\begin{array}{l}\text { Logaritmo da quantidade consumida de } \\
\text { agrotóxicos por área plantada (Kg/ha) no Brasil. }\end{array}$ & Série anual de 1990 a 2016. & $\begin{array}{l}\text { FAOSTAT } \\
(2018)\end{array}$ \\
\hline lagrotx_EUA & $\begin{array}{l}\text { Logaritmo da quantidade consumida de } \\
\text { agrotóxicos por área plantada }(\mathrm{Kg} / \mathrm{ha}) \text { nos EUA. }\end{array}$ & Série anual de 1990 a 2016. & $\begin{array}{l}\text { FAOSTAT } \\
(2018)\end{array}$ \\
\hline lagrotx_EU & $\begin{array}{l}\text { Logaritmo da quantidade consumida de } \\
\text { agrotóxicos por área plantada }(\mathrm{Kg} / \mathrm{ha}) \text { na UE. }\end{array}$ & Série anual de 1990 a 2016. & $\begin{array}{l}\text { FAOSTAT } \\
(2018)\end{array}$ \\
\hline lprod_BR & $\begin{array}{l}\text { Logaritmo da quantidade da produção agrícola } \\
\text { por área plantada - Produtividade (Kg/ha). }\end{array}$ & $\begin{array}{c}\text { Série anual de } 1990 \text { a } 2016 \text {. } \\
\text { Consideram-se as } 38 \text { principais culturas }{ }^{1} \\
\text { mencionadas por Bacha (2018). Essas culturas } \\
\text { representam mais do que } 95 \% \text { da produção agrícola. }\end{array}$ & $\begin{array}{l}\text { IBGE } \\
(2019)\end{array}$ \\
\hline
\end{tabular}

Fonte: Elaboração própria. Os dados utilizados estão nas Tabelas 17 e 18 do apêndice a este artigo

${ }^{1}$ Essas 38 culturas são: abacate, algodão-arbóreo, algodão-herbáceo, alho, amendoim, arroz, aveia, batata, cacau, café, cana, castanha, cebola, centeio, cevada, coco, feijão, fumo, goiaba, guaraná, juta, laranja, limão, maçã, malva, mamona, mandioca, manga, maracujá, milho, pimenta, sisal, soja, sorgo, tangerina, tomate, trigo e uva. Em alguns anos da série analisada, o IBGE não publicou dados de quilogramas para algumas frutas e sim a quantidade das mesmas. Para tanto, segundo Bacha (2018), utilizou-se valores de gramas para essas frutas de modo a obter os valores em kg. 
Conforme Enders (2010), a estatística $\lambda$-traço é dada por (Equação 1):

$$
\lambda_{\text {Traço }}(r)=-T^{*} \sum_{i=r+1}^{n} \ln \left(1-\hat{\lambda}_{i}\right)
$$

Sendo que $T^{*}$ é o número de observações; $\hat{\lambda}$ são os valores estimados das raízes características (valores esses que verificam a convergência das séries); e $r$ é o rank de cointegração.

O teste $\lambda$-traço é realizado de forma sequencial tendo como hipótese nula o número de vetores de cointegração ser menor ou igual a $r$. A hipótese alternativa é de que o número de vetores seja maior que $r$. Os valores críticos das estatísticas $\lambda$-traço são obtidos usando a abordagem de Monte Carlo. Caso existam $n$ variáveis, é possível existir no máximo $n$ - 1 vetores cointegrados (Mackinnon, 1996).

Os testes de cointegração permitem avaliar a existência, ou não, de relações (equilíbrio) de longo prazo tanto no uso de agrotóxicos entre o Brasil, Estados Unidos e União Europeia quanto na relação do uso de agrotóxicos com a produtividade agrícola no Brasil.

Para analisar a dinâmica entre a produtividade agrícola do Brasil e o seu consumo de agrotóxicos utilizou-se o modelo de Autorregressão Vetorial Estrutural (SVAR). Tal modelo foi proposto por Sims (1986) e Bernanke (1986), em 1986, e ele possibilita modelar choques não antecipados a partir de embasamento analítico ou teórico.

O modelo SVAR, conforme apresentado por Enders (2010), é apresentado como (Equação 2):

$$
\boldsymbol{A}_{0} \boldsymbol{x}_{\boldsymbol{t}}=\boldsymbol{\alpha}+\sum_{i=1}^{p} \boldsymbol{A}_{i} \boldsymbol{x}_{\boldsymbol{t}-1}+\boldsymbol{\varepsilon}_{\boldsymbol{t}}
$$

Sendo que $p$ é a ordem de defasagem; $\boldsymbol{\varepsilon}_{\boldsymbol{t}}$ é o vetor, $\mathrm{n} \times 1$, de inovações (choques) estruturais serialmente e mutualmente não correlacionadas; $\boldsymbol{A}_{0}, \boldsymbol{A}_{i}$ e $\boldsymbol{\alpha}$ são matrizes, $\mathrm{n}$ x n, de coeficientes desconhecidos a serem estimados; e $\boldsymbol{x}_{\boldsymbol{t}}$ é vetor das variáveis, isto é, $\boldsymbol{x}_{\boldsymbol{t}}=$ (produtividade agrícola, consumo de agrotóxicos).

Ao pré-multiplicar a Equação (2) por $\boldsymbol{A}_{0}^{-1}$, tem-se a forma reduzida dada por (Equação 3):

$$
\boldsymbol{x}_{\boldsymbol{t}}=\boldsymbol{A}_{0}^{-1} \boldsymbol{\alpha}+\sum_{i=1}^{p} \boldsymbol{A}_{0}^{-1} \boldsymbol{A}_{i} \boldsymbol{x}_{\boldsymbol{t}-1}+\boldsymbol{e}_{\boldsymbol{t}}
$$

Sendo que $\boldsymbol{e}_{\boldsymbol{t}}$ é o resíduo estimado na forma reduzida, dado por (Equação 4):
$\boldsymbol{e}_{t}=A_{0}^{-1} \varepsilon_{t}$

Em que $\boldsymbol{A}_{0}^{-1}$ é a matriz que irá impor as restrições teóricas à estrutura, ou seja, essa matriz permitirá estabelecer os efeitos contemporâneos de um choque não antecipado de uma variável sobre outra(s).

Diferentemente do VAR, em que $\boldsymbol{A}_{0}^{-1}$ exige uma ordenação prévia derivada da Decomposição de Choleski ( $\frac{n^{2}-n}{2}$ restrições), o VAR Estrutural permite com que a imposição dessas restrições seja de acordo com as relações analíticas ou teóricas propostas (Hamilton, 1994).

Assim, supõe-se a seguinte relação contemporânea: considera-se que um impacto no consumo de agrotóxicos influencie contemporaneamente a produtividade agrícola; mas a produtividade agrícola não impacta contemporaneamente o consumo de agrotóxicos.

Logo, os erros na forma reduzida, $\boldsymbol{e}_{t}$ (Equação 4), podem ser decompostos nos seguintes componentes (Equação 5):

$e_{t} \equiv\left[\begin{array}{c}e_{t}^{\Delta \text { Produtividade Agricola }} \\ e_{t}^{\text {AConsumo de Agrotóxicos }}\end{array}\right]=\left[\begin{array}{cc}1 & a_{12} \\ 0 & 1\end{array}\right]\left[\begin{array}{c}\varepsilon_{t}^{\text {Choque na produtividade agricola }} \\ \varepsilon_{t}^{\text {Choque no consumo de agrotóxicos }}\end{array}\right]$

Em que, o zero na $\boldsymbol{A}_{0}^{-1}$ matriz da Equação (5) significa que não há efeito contemporâneo.

Com isso, estabelecem-se as funções impulso-resposta, as quais buscam investigar a evolução do efeito de um choque não antecipado tanto nela própria, como na outra variável.

No entanto, se as variáveis do modelo forem cointegradas há a necessidade de empregar o Modelo de Correção de Erros Estrutural (SVEC), que é um ajuste do modelo VAR que adapta a dinâmica do curto prazo das variáveis do sistema na estrutura de equilíbrio de longo prazo.

Logo, ao ajustar equação (2), tem-se o seguinte VAR com Correção de Erro (Equação 6):

$$
A_{0} \Delta \boldsymbol{X}_{t}=\boldsymbol{\alpha}+\boldsymbol{\Pi} \boldsymbol{X}_{t}+\sum_{i=1}^{p-1} \boldsymbol{\Gamma}_{i} \Delta \boldsymbol{X}_{t-i}+\boldsymbol{\varepsilon}_{t}
$$

Sendo $\boldsymbol{\Pi}=-\left(\boldsymbol{I}-\boldsymbol{A}_{1}-\ldots-\boldsymbol{A}_{p}\right)$ e $\boldsymbol{\Gamma}_{i}=-\left(\boldsymbol{A}_{i+1}+\ldots+\boldsymbol{A}_{p}\right)$ para $i=1, \ldots$, até a defasagem p. $\boldsymbol{X}_{t}$ é o vetor com n variáveis (matriz n x 1), $\boldsymbol{A}_{1}$ a $\boldsymbol{A}_{p}$ são as matrizes de parâmetros (n x n) e $I$ é uma matriz identidade (n x n). Mais detalhe desse método encontram-se em Engle e Granger (1987). 
E com o intuito de compreender a proporção de movimento de uma variável a um choque nela própria, versus o choque em outras variáveis, calcula-se a decomposição da variância do erro padrão, expressa a seguir (Equação 7):

$F D V(v, k, j)=\frac{\sum_{i=0}^{j-1} \theta_{i v k}^{2} \sigma_{k}^{2}}{\sum_{i=0}^{j-l} \sum_{s=1}^{n} \theta_{i v s}^{2} \sigma_{s}^{2}} * 100$

Sendo que $\theta_{i v s}$ é o elemento da matriz de parâmetros, $\theta_{i}$, na posição $(v, s)$ e $\sigma_{s}^{2}$ é o variância do erro de previsão da variável $S, \sigma_{k}^{2}$ é a variância de previsão $j$-períodos à frente da variável $v$.

O cálculo desta expressão (7) fornece a porcentagem da variância de erro de previsão para a variável $v$ a $j$-períodos a frente do choque.

Todos os procedimentos metodológicos supra apresentados foram realizados usando o software R tendo como base o artigo de Pfaff (2008).

\section{RESULTADOS E DISCUSSÃO}

Esta seção compõe-se de três itens. Inicialmente, comenta-se sobre os resultados obtidos da análise estatística descritiva dos dados utilizados. Em seguida, analisa-se a cointegração das séries sobre o consumo de agrotóxicos por hectare nos EUA, Europa e Brasil. E, por fim, aplica-se o modelo SVAR para avaliar a relação entre o consumo de agrotóxicos e a produtividade agrícola do Brasil.

\subsection{Análise estatística descritiva dos dados utilizados}

O Brasil é caracterizado como sendo um dos maiores consumidores de agrotóxicos (quando mensurado em peso) do mundo, já ultrapassando em 2009 o consumo total da União Europeia, mas ainda ficando abaixo do consumo dos Estados Unidos (Figura 1). É expressiva a ascensão do consumo anual brasileiro de agrotóxicos desde 1990 (Figura 1 e 2).

Ao se comparar o consumo dos agrotóxicos por área plantada, as posições dos países se invertem. A União Europeia é a que mais consome agrotóxicos por hectare de área agrícola, com consumo médio de $1,902 \mathrm{Kg} /$ ha (Tabela 1). Em seguida situa-se o Brasil, o qual apresenta crescimento neste uso, tendo ultrapassado os Estados Unidos em 2007 (Figura 2). No Brasil, o máximo consumo de agrotóxicos ocorreu em 2015 , com $1,393 \mathrm{Kg} /$ ha (Tabela 1). Os EUA mantêm, no período analisado, um consumo de agrotóxicos próximo a $0,983 \mathrm{~kg} / \mathrm{ha}$.

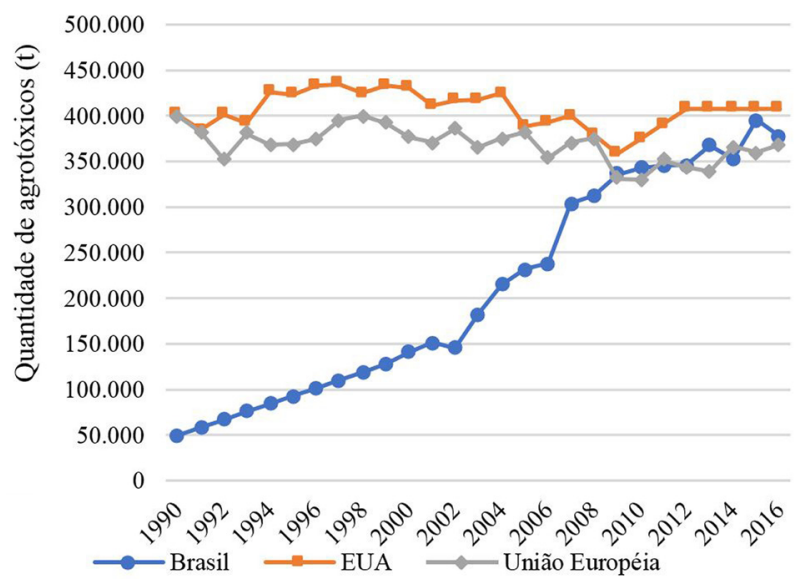

FIGURA 1 - Quantidade de agrotóxicos consumidos no Brasil, Estados Unidos e União Europeia

Fonte: Gráfico elaborado a partir de dados da FAOSTAT (2018)

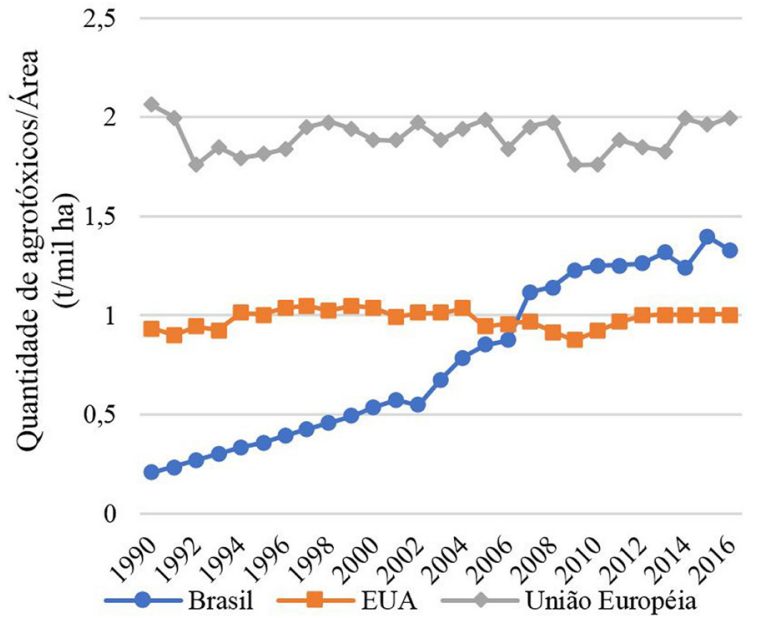

FIGURA 2 - Quantidade de agrotóxicos consumidos por hectare de área agrícola no Brasil, Estados Unidos e União Europeia

Fonte: Gráfico elaborado a partir de dados da FAOSTAT (2018)

No Brasil e nos Estados Unidos, os herbicidas são os tipos de agrotóxicos mais utilizados, representando entre $50 \%$ e $60 \%$ do total consumido de agrotóxicos durante o período em análise. E, na União Europeia, os fungicidas e os bactericidas são os agrotóxicos mais empregados, representando entre $40 \%$ a $45 \%$ do total consumido de agrotóxicos.

Embora o Brasil, os Estados Unidos e a União Europeia possuam diferenças quanto ao uso de agrotóxicos, cada qual com as suas respectivas regulamentações de uso, ao se observar as Figuras 1 e 2 
parece haver que os três países (ou bloco de países) caminham para uma estabilização de crescimento no uso desses produtos. Dentre as séries, o Brasil iniciou a estabilização em 2009.

O aumento do uso de agrotóxicos no Brasil se associa ao aumento da produtividade das lavouras (como pode ser observado na Figura 3). Há visível correlação entre a quantidade utilizada de agrotóxicos no Brasil e a produtividade de suas lavouras. O que pode ser confirmada através do coeficiente de correlação de Spearman cujo valor foi de 0,9206 , considerando o período de 1990 a 2016.

\subsection{Resultados dos testes de cointegração}

A análise da estacionariedade das séries sobre o consumo de agrotóxicos por hectare de área plantada no Brasil, EUA e EU foi realizada, a priori, pelo teste de Dickey e Pantula, cuja hipótese nula testada é a presença de duas raízes unitárias em cada uma das séries de consumo de agrotóxicos por hectare nas três regiões, testando os componentes determinísticos de tendência, constante, e sem nenhum. Os resultados indicaram a rejeição da presença de duas raízes unitárias para os países analisados, conforme mostrado na Tabela 2 .

Para analisar a presença de uma raiz unitária, utilizou-se o teste DF-GLS (Tabela 3). Pode-se constatar que todas as séries de quantidade consumida de agrotóxicos com os respectivos componentes deterministas não rejeitaram a hipótese nula ao nível de $1 \%$ ou $5 \%$, indicando, assim, a presença de uma raiz unitária para todas as séries. À vista disso e para melhor verificação da ordem de integração, realizou-se o teste DF-GLS com as variáveis na primeira diferença. De acordo com os resultados deste teste (Tabela 3) as três séries apresentaram-se estacionárias quando acrescido os componentes deterministas, ou seja, as series são integradas de ordem 1 .

TABELA 1 - Estatísticas descritivas das séries da quantidade consumida de agrotóxicos (kg/ha) nas diferentes regiões e da produtividade agrícola no Brasil

\begin{tabular}{ccccc}
\hline \multirow{2}{*}{$\begin{array}{c}\text { Indicador } \\
\text { estatístico }\end{array}$} & \multicolumn{3}{c}{ Kg de agrotóxicos por hectare } & \multirow{2}{*}{ Produtividade agrícola no Brasil (kg/ha) } \\
\cline { 2 - 4 } & EUA & União Europeia & Brasil & \\
\hline Média & 0,983 & 1,902 & 0,773 & $11.206,667$ \\
Mediana & 1,000 & 1,888 & 0,680 & 10.387 \\
Máxima & 1,048 & 2,059 & 1,393 & 14.985 \\
Mínima & 0,874 & 1,756 & 0,206 & 7.610 \\
\hline
\end{tabular}

Fonte: Dados gerados na pesquisa

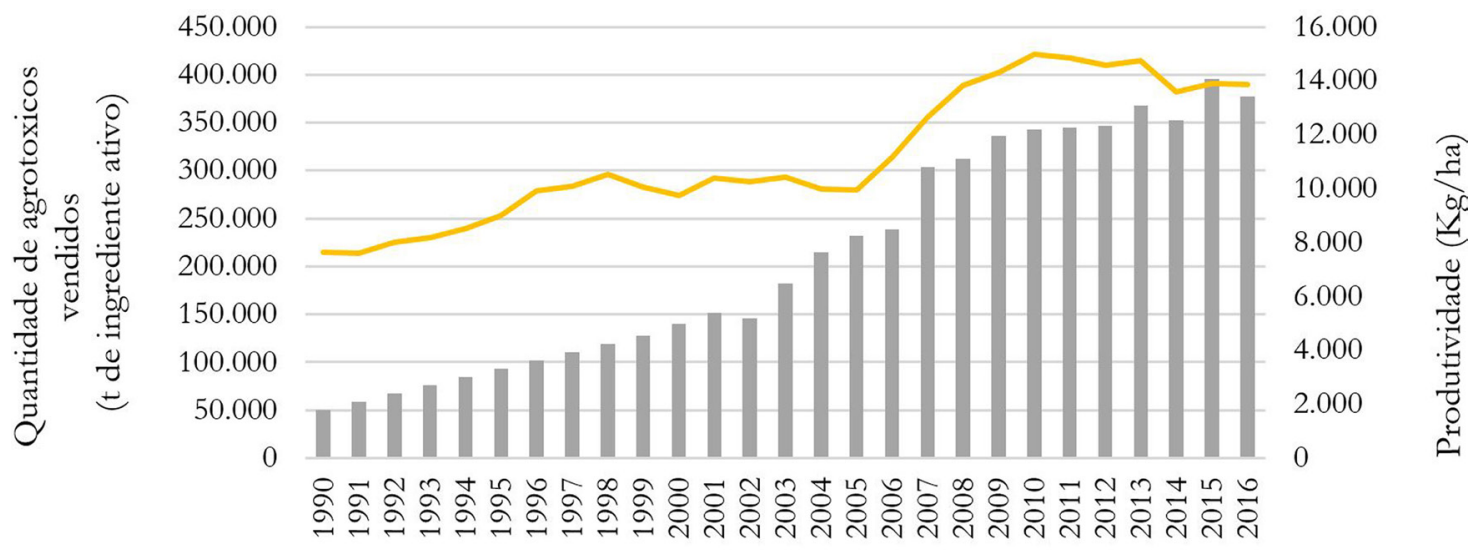

Agrotóxicos vendidos Produtividade

FIGURA 3 - Quantidade vendidas de agrotóxicos e produtividade agrícola no Brasil Fonte: Elaborado a partir dos dados do IBRE-FGV (2018), FAOSTAT/FAO (2018) e IBGE (2018) 
TABELA 2 - Resultados do teste de Dickey e Pantula para a hipótese nula de duas raízes unitárias nas séries das variáveis de quantidade consumida de agrotóxicos por área plantada

\begin{tabular}{|c|c|c|c|c|c|c|}
\hline \multirow{2}{*}{ Série } & \multirow{2}{*}{$\begin{array}{l}\text { Componente } \\
\text { determinista }\end{array}$} & \multirow{2}{*}{$\begin{array}{c}\mathrm{N}^{0} \text { de } \\
\text { defasagens }\end{array}$} & \multirow{2}{*}{$\begin{array}{c}\text { Estatística } \\
\text { do teste }\end{array}$} & \multicolumn{2}{|c|}{ Valores críticos $^{1}$} & \multirow{2}{*}{ Resultados da significância $\mathbf{H 0}$} \\
\hline & & & & $5 \%$ & $1 \%$ & \\
\hline \multirow{3}{*}{ lagrotx_BR } & Tendência & 0 & $-6,124$ & $-3,588$ & 4,339 & Rejeita H0: I(2) \\
\hline & Constante & 0 & $-5,076$ & $-2,976$ & $-3,700$ & Rejeita H0: I(2) $)^{* *}$ \\
\hline & Nenhum & 2 & $-4,408$ & $-1,954$ & $-2,653$ & Rejeita H0: I $(2)^{* *}$ \\
\hline \multirow{3}{*}{ lagrotx_EUA } & Tendência & 0 & $-5,661$ & $-3,588$ & 4,339 & Rejeita H0: I $(2)^{* *}$ \\
\hline & Constante & 0 & $-5,718$ & $-2,976$ & $-3,700$ & Rejeita H0: I(2)** \\
\hline & Nenhum & 0 & $-5,763$ & $-1,954$ & $-2,653$ & Rejeita H0: I(2) ${ }^{* *}$ \\
\hline \multirow{3}{*}{ lagrotx_UE } & Tendência & 0 & $-6,126$ & $-3,588$ & 4,339 & Rejeita H0: I $(2)^{* *}$ \\
\hline & Constante & 0 & $-6,069$ & $-2,976$ & $-3,700$ & Rejeita H0: I(2)** \\
\hline & Nenhum & 0 & $-6,203$ & $-1,954$ & $-2,653$ & Rejeita H0: I(2) ${ }^{* *}$ \\
\hline
\end{tabular}

Nota: ${ }^{* *} \mathrm{e}$ * denotam significância de 1\% e 5\% respectivamente; ${ }^{1}$ valores críticos obtidos em Mackinnon (1996).

Fonte: Dados gerados na pesquisa

TABELA 3 - Resultados do teste DF-GLS para a hipótese nula de uma raiz unitária das séries sobre quantidades consumidas de agrotóxicos por área plantada

\begin{tabular}{|c|c|c|c|c|c|c|}
\hline \multirow{2}{*}{ Série } & \multirow{2}{*}{$\begin{array}{l}\text { Componente } \\
\text { determinista }\end{array}$} & \multirow{2}{*}{$\begin{array}{c}\mathrm{N}^{0} \text { de } \\
\text { defasagens }\end{array}$} & \multirow{2}{*}{$\begin{array}{l}\text { Estatística } \\
\text { do teste }\end{array}$} & \multicolumn{2}{|c|}{ Valores críticos ${ }^{2}$} & \multirow{2}{*}{$\begin{array}{c}\text { Resultados da significância } \\
\text { H0 }\end{array}$} \\
\hline & & & & $5 \%$ & $1 \%$ & \\
\hline \multirow{3}{*}{ lagrotx_BR } & Tendência & 4 & $-2,011$ & $-3,19$ & $-3,77$ & Não rejeita H0: $\mathrm{I}(1)^{* *}$ \\
\hline & Constante & 4 & $-0,506$ & $-1,95$ & $-2,65$ & Não rejeita H0: I(1)** \\
\hline & Nenhum $^{1}$ & 4 & $-1,048$ & $-1,95$ & $-2,62$ & Não rejeita $\mathrm{H} 0: \mathrm{I}(1)^{* *}$ \\
\hline \multirow{3}{*}{ lagrotx_EUA } & Tendência & 4 & $-2,215$ & $-3,19$ & $-3,77$ & Não rejeita H0: I(1)** \\
\hline & Constante & 4 & $-2,187$ & $-1,95$ & $-2,65$ & Não rejeita H0: I(1) \\
\hline & Nenhum $^{1}$ & 1 & $-2,406$ & $-1,95$ & $-2,62$ & Não rejeita H0: I(1)* \\
\hline \multirow{3}{*}{ lagrotx_UE } & Tendência & 4 & $-3,097$ & $-3,19$ & $-3,77$ & Não rejeita H0: I(1) ${ }^{* *}$ \\
\hline & Constante & 4 & $-2,306$ & $-1,95$ & $-2,65$ & Não rejeita H0: I(1)* \\
\hline & Nenhum $^{1}$ & 3 & $-0,566$ & $-1,95$ & $-2,62$ & Não rejeita H0: I(1) ${ }^{* *}$ \\
\hline \multirow{3}{*}{$\Delta$ lagrotx_BR } & Tendência & 1 & $-3,676$ & $-3,19$ & $-3,77$ & Rejeita H0: I(1) ${ }^{*}$ \\
\hline & Constante & 1 & $-2,750$ & $-1,95$ & $-2,65$ & Rejeita H0: I(1)** \\
\hline & Nenhum $^{1}$ & 3 & $-1,394$ & $-1,95$ & $-2,62$ & Não rejeita $\mathrm{H} 0: \mathrm{I}(1)^{* *}$ \\
\hline \multirow{3}{*}{$\Delta$ lagrotx_EUA } & Tendência & 0 & $-5,626$ & $-3,19$ & $-3,77$ & Rejeita H0: I(1)** \\
\hline & Constante & 1 & $-3,016$ & $-1,95$ & $-2,65$ & Rejeita H0: I(1) ${ }^{* *}$ \\
\hline & Nenhum $^{1}$ & 1 & $-3,451$ & $-1,95$ & $-2,62$ & Rejeita H0: I(1)** \\
\hline \multirow{3}{*}{$\Delta$ lagrotx_UE } & Tendência & 0 & $-6,380$ & $-3,19$ & $-3,77$ & Rejeita H0: I(1) ${ }^{* *}$ \\
\hline & Constante & 0 & $-6,072$ & $-1,95$ & $-2,65$ & Rejeita H0: I(1)** \\
\hline & Nenhum $^{1}$ & 2 & $-2,829$ & $-1,95$ & $-2,62$ & Rejeita H0: I(1)** \\
\hline
\end{tabular}

Nota: $\Delta$ representa a série na primeira diferença; ${ }^{* *},{ }^{*}$ denotam significância de $1 \%$ e $5 \%$ respectivamente; ${ }^{1}$ na ausência de termos deterministas, o teste DF-GLS é equivalente ao teste ADF (1981); ${ }^{2}$ valores críticos obtidos em Mackinnon (1996).

Fonte: Dados gerados na pesquisa

Organizações Rurais \& Agroindustriais, Lavras, v. 23, e1687, 2021 
Após constatar que todas as três séries (do Brasil, EUA e União Europeia) de consumo de agrotóxicos por hectare são integradas de ordem 1, realizou-se o teste de cointegração. Primeiramente, determinou-se o número de defasagem das variáveis em conjunto, no qual para os quatro critérios adotados (critério de Akaike, AIC; critério de Hannan e Quinn, HQ; critério de Schwarz, SC; e o critério de erro de previsão final, FPE), existem três defasagens (Tabela 4). A definição das defasagens é identificada pelo valor menor entre cada critério.

TABELA 4 - Determinação do número de defasagens para o teste de cointegração do consumo de agrotóxicos no Brasil, Estados Unidos e União Europeia

\begin{tabular}{ccccc}
\hline \multirow{2}{*}{$\begin{array}{c}\mathbf{N}^{0} \text { de } \\
\text { defasagens }\end{array}$} & \multicolumn{4}{c}{ Critérios utilizados para seleção } \\
\cline { 2 - 5 } & AIC & HQ & SC & FPE \\
\hline 1 & $-18,549$ & $-18,409$ & $-17,954$ & $8,91 \mathrm{E}-09$ \\
2 & $-18,580$ & $-18,335$ & $-17,539$ & $9,13 \mathrm{E}-09$ \\
3 & $-20,269^{*}$ & $-19,918^{*}$ & $-18,781^{*}$ & $1,95 \mathrm{E}-09^{*}$ \\
4 & $-19,874$ & $-19,418$ & $-17,939$ & $3,97 \mathrm{E}-09$ \\
5 & $-19,832$ & $-19,272$ & $-17,452$ & $7,88 \mathrm{E}-09$ \\
\hline
\end{tabular}

Nota: ${ }^{~}$ ordem sugeria pelo Critério; AIC $=$ Critério de Akaike; HQ = Critério de Hannan e Quinn; SC = Critério de Schwarz; e $\mathrm{FPE}=$ erro de previsão final.

Fonte: Dados gerados na pesquisa

Ao se realizar o teste de cointegração JohansenGranger sem a inclusão de termos determinísticos na matriz de cointegração, uma vez que o diagnóstico deste modelo apresentou-se melhor, os valores indicaram a existência de pelo menos dois vetor de cointegração (Tabela 6). Tal resultado é verificado de forma sequencial. Analisa-se primeiro se H0: $r=0$, a qual foi rejeitada ao nível de $1 \%$ de significância estatística. Dado esta rejeição, testa-se em seguida se $\mathrm{H} 0: \mathrm{r} \leq 1$, a qual também foi rejeitada ao nível de $1 \%$ de significância estatística. Com a rejeição desse último, testa em seguida se $\mathrm{H} 0$ : $\mathrm{r} \leq 2$, a qual não foi rejeitada ao nível de $1 \%$ de significância estatística. Isso sugere que o consumo de agrotóxicos por área para as três regiões (Brasil, EUA e União Europeia) apresenta equilíbrio de longo-prazo.

Apesar da alta correlação ao longo dos anos entre as séries consumo de agrotóxicos no Brasil por área plantada versus a produtividade agrícola no Brasil (Figura 3), também se analisa a possível existência de equilíbrio de longo-prazo entre essas duas variáveis, considerando o que se observa na segunda década do século XXI.
Para tanto, ao analisar os resultados do teste de Dickey e Pantula determinou-se que a série de produtividade no Brasil apresenta, para todos os componentes determinista, a rejeição da presença de duas raízes unitárias (Tabela 6), assim como a quantidade consumida de agrotóxicos por área plantada (já constatado na Tabela 2).

TABELA 5 - Determinação do número de defasagens para o teste de cointegração do consumo de agrotóxicos por hectare no Brasil, Estados Unidos e União Europeia

\begin{tabular}{ccccc}
\hline \multicolumn{2}{c}{ Hipótese } & \multirow{2}{*}{$\begin{array}{c}\text { Estatística } \\
\text { do teste }\end{array}$} & \multicolumn{2}{c}{ Valores críticos ${ }^{\mathbf{1}}$} \\
\cline { 1 - 3 } Nula & Alternativa & & $\mathbf{5 \%}$ & $\mathbf{1 \%}$ \\
\hline $\mathrm{r}=0$ & $\mathrm{r}>0$ & 56,32 & 31,52 & 37,22 \\
$\mathrm{r} \leq 1$ & $\mathrm{r}>1$ & 25,31 & 17,95 & 23,52 \\
$\mathrm{r} \leq 2$ & $\mathrm{r}>2$ & 6,72 & 8,18 & 11,65 \\
\hline
\end{tabular}

Nota: r é o rank de cointegração; ${ }^{1}$ valores críticos obtidos em Osterwald-Lenun (1992).

Fonte: Dados gerados na pesquisa

E ao realizar o teste DF-GLS, os resultados indicaram a presença de uma raiz unitária (Tabela 7) para a série de produtividade agrícola no Brasil, coincidindo com o constatado para a quantidade consumida de agrotóxicos por área. E ao realizar os testes DF-GLS com e sem inclusão do componente determinista para a série de produtividade agrícola no Brasil, medida na sua primeira diferença, houve rejeição da hipótese nula (Tabela 7). Com isso certifica-se que a série é integrada de ordem 1.

Em seguida, examina-se o número de defasagem das duas variáveis (produtividade agrícola e consumo por hectare de agrotóxicos) conjuntamente. Os critérios de Akaike (AIC) e de Hannan (HQ) indicaram 5 defasagens. E os critérios de Schwarz (SC) e o do erro previsão final (FPE) indicaram 4 defasagens. Em virtude do critério de Schwarz ser parcimonioso com o número de variáveis independentes e preservando o pouco número de graus de liberdades, assumiu-se como tendo 4 defasagens (Tabela 8).

O teste de cointegração com a constante fora da matriz sugere a presença de pelo menos 1 vetor de cointegração (Tabela 9). Primeiramente, testou-se H0: r=0, a qual foi rejeitada ao nível de $1 \%$ de significância estatística. Em seguida testou $\mathrm{H} 0: \mathrm{r} \leq 1$, a qual não rejeitada ao nível de $1 \%$ de significância estatística. Isto indica, portanto, a presença de equilíbrio entre as duas variáveis, como o esperado.

Diante dos resultados, houve a evidência da presença de equilíbrio de longo-prazo (dado o teste constatar a 
presença de um vetor de cointegração), para os dois casos: $\left(1^{\circ}\right)$ entre o consumo de agrotóxicos no Brasil, nos Estados Unidos e na União Europeia e $\left(2^{\circ}\right)$ entre o consumo de agrotóxicos no Brasil e a produtividade agrícola brasileira. Isso implica dizer que o modelo que melhor representa a relação das variáveis analisadas é o modelo Vetor de Correção de erros (VEC). Os diagnósticos de ambos os modelos se mostraram adequados, isto é, há ausência de autocorrelação e os resíduos têm distribuição normal (Tabelas 15 e 16 - Anexo).

O modelo VEC é uma versão do VAR que corrige o problema das variáveis omitidas relevantes, permitindo estimar a dinâmica de curto-prazo das variáveis do sistema, mantendo o equilíbrio de longo-prazo entre as variáveis (Enders, 2010).

TABELA 6 - Resultados do teste de Dickey e Pantula para a hipótese nula de duas raízes unitárias na série da produtividade no Brasil

\begin{tabular}{ccccccc}
\hline \multirow{2}{*}{ Série } & \multirow{2}{*}{$\begin{array}{c}\text { Componente } \\
\text { determinista }\end{array}$} & \multirow{2}{*}{ No de defasagens } & \multirow{2}{*}{ Estatística do teste } & \multicolumn{2}{c}{ Valores críticos $^{\mathbf{1}}$} & \multirow{2}{*}{ Resultados da significância Ho $^{*}$} \\
\hline \multirow{2}{*}{$\begin{array}{c}\text { Produtividade } \\
\text { no Brasil }\end{array}$} & Tendência & 0 & $-3,594$ & $-3,588$ & $-4,339$ & Rejeita H0: I $(2)^{*}$ \\
& Constante & 0 & $-3,513$ & $-2,976$ & $-3,700$ & Rejeita H0: I(2)* \\
& Nenhum & 0 & $-3,085$ & $-1,954$ & $-2,653$ & Rejeita H0: I(2)** \\
\hline
\end{tabular}

Nota: ${ }^{* *} \mathrm{e}^{*}$ denotam significância de $1 \%$ e 5\% respectivamente; ${ }^{1}$ valores críticos obtidos em Mackinnon (1996).

Fonte: Dados gerados na pesquisa

TABELA 7 - Resultados do teste DF-GLS para a hipótese nula de uma raiz unitária séries na série da produtividade agrícola brasileira

\begin{tabular}{|c|c|c|c|c|c|c|}
\hline \multirow{2}{*}{ Série } & \multirow{2}{*}{$\begin{array}{l}\text { Componente } \\
\text { determinista }\end{array}$} & \multirow{2}{*}{$\begin{array}{c}\mathrm{N}^{0} \text { de } \\
\text { defasagens }\end{array}$} & \multirow{2}{*}{ Estatística do teste } & \multicolumn{2}{|c|}{ Valores críticos $^{2}$} & \multirow{2}{*}{ Resultados da significância H0 } \\
\hline & & & & $5 \%$ & $1 \%$ & \\
\hline \multirow{3}{*}{ lprod_BR } & Tendência & 4 & $-2,667$ & $-3,19$ & $-3,77$ & Não rejeita H0: I(1) \\
\hline & Constante & 4 & $-0,411$ & $-1,95$ & $-2,65$ & Não rejeita H0: I(1) ${ }^{* *}$ \\
\hline & Nenhum $^{1}$ & 1 & 1,476 & $-1,95$ & $-2,62$ & Não rejeita H0: I(1) ${ }^{* *}$ \\
\hline \multirow{3}{*}{$\Delta$ lprod_BR } & Tendência & 0 & $-3,692$ & $-3,19$ & $-3,77$ & Rejeita H0: I(1) ${ }^{*}$ \\
\hline & Constante & 0 & $-3,504$ & $-1,95$ & $-2,65$ & Rejeita H0: I(1) ${ }^{* *}$ \\
\hline & Nenhum ${ }^{1}$ & 1 & $-2,216$ & $-1,95$ & $-2,62$ & Rejeita H0: I(1) ${ }^{*}$ \\
\hline
\end{tabular}

Nota: $\Delta$ representa a série na primeira diferença; ${ }^{* *},{ }^{*}$ denotam significância de $1 \%$ e $5 \%$ respectivamente; ${ }^{1}$ na ausência de termos deterministas, o teste DF-GLS é equivalente ao teste ADF (1981); ${ }^{2}$ valores críticos obtidos em Mackinnon (1996).

Fonte: Dados gerados na pesquisa

TABELA 8 - Determinação do número de defasagens para o teste de cointegração do consumo de agrotóxicos no Brasil e a produtividade agrícola brasileira

\begin{tabular}{ccccc}
\hline \multirow{2}{*}{ N $^{0}$ de defasagens } & \multicolumn{4}{c}{ Critérios utilizados para seleção } \\
\cline { 2 - 4 } & AIC & HQ & SC & FPE \\
\hline 1 & $-11,029$ & $-10,959$ & $-10,732$ & $1,63 \mathrm{E}-05$ \\
2 & $-11,212$ & $-11,095$ & $-10,716$ & $1,37 \mathrm{E}-05$ \\
3 & $-11,566$ & $-11,402$ & $-10,871$ & $9,93 \mathrm{E}-06$ \\
4 & $-12,253$ & $-12,043$ & $-11,360^{*}$ & $5,28 \mathrm{E}-06^{*}$ \\
5 & $-12,336^{*}$ & $-12,079^{*}$ & $-11,245$ & $5,35 \mathrm{E}-06$ \\
\hline
\end{tabular}

Nota: ${ }^{*}$ ordem sugeria pelo Critério; AIC = Critério de Akaike; HQ = Critério de Hannan e Quinn; SC = Critério de Schwarz; e FPE = erro de previsão final.

Fonte: Dados gerados na pesquisa

Organizações Rurais \& Agroindustriais, Lavras, v. 23, e1687, 2021 
TABELA 9 - Determinação do número de defasagens para o teste de cointegração do consumo de agrotóxicos no Brasil e a produtividade agrícola brasileira

\begin{tabular}{|c|c|c|c|c|}
\hline \multicolumn{2}{|c|}{ Hipótese } & \multirow{2}{*}{$\begin{array}{c}\text { Estatística } \\
\text { do teste }\end{array}$} & \multicolumn{2}{|c|}{ Valores críticos $^{1}$} \\
\hline Nula & Alternativa & & $5 \%$ & $1 \%$ \\
\hline $\mathrm{r}=0$ & $r>0$ & 41,44 & 17,95 & 23,52 \\
\hline$r \leq 1$ & $r>1$ & 3,86 & 8,18 & 11,65 \\
\hline
\end{tabular}

Nota: r é o rank de cointegração; ${ }^{1}$ valores críticos obtidos em Osterwald-Lenun (1992).

Fonte: Dados gerados na pesquisa

No presente estudo deu-se continuidade para a estimação do modelo VEC, através da metodologia SVEC, apenas para a relação entre a produtividade agrícola do Brasil e seu consumo de agrotóxicos. Não se procede ao mesmo para analisar a relação do consumo de agrotóxicos entre diferentes países, pois isto envolveria diversos fatores (político, ambiental, social, entre outros) que não o foco do artigo.

\subsection{Resultados do modelo SVEC}

O emprego do modelo SVEC usando as variáveis produtividade agrícola do Brasil e consumo de agrotóxicos por hectare possibilitou a análise do comportamento de curto e longo-prazo entre essas duas variáveis.

A relação contemporânea entre o impacto do maior uso de agrotóxicos e a produtividade agrícola mostrou-se negativa, ou seja, o aumento de 10\% (acréscimo de 0,1 desvio padrão) no consumo de agrotóxicos associou-se à redução contemporânea da produtividade em 3,422\% (coeficiente este estatisticamente significativo a nível de $10 \%$, ver Tabela 10). Esta relação negativa pode ser fruto da ameaça de queda da produtividade. Os agrotóxicos são usados para evitar a queda expressiva da produtividade e são usados em maior intensidade quando há infestação de doenças e pragas já reduzindo significativamente a produtividade. Por conseguinte, o maior uso de agrotóxicos se dá quando já ocorre queda de produtividade e não para aumentar a mesma. Mas, a continuidade dos efeitos do agrotóxico no solo garante o retorno da produtividade no ciclo produtivo seguinte. Por exemplo, se há uma infestação de ferrugem da soja que já está implicando queda da produtividade, o maior uso do pesticida não evitará certa perda de produtividade no presente momento, mas evitará uma perda maior.

Ao analisar a dinâmica da função impulso resposta (Tabela 11), observa-se que no segundo período após o choque de $10 \%$ no consumo de agrotóxicos há uma redução na variação desse insumo em 4,88\%. Ademais, neste mesmo período ocorre a redução da produtividade (em -4,95\%). Esse evento, de redução da produtividade, pode estar relacionado à existência da enfermidade ainda no solo. De acordo com Reis, Casa e Bianchin (2011), o cultivo subsequente de uma mesma cultura na área aumenta a probabilidade de reincidência do ataque de praga ou de doença. Isto por que os restos culturais presentes no solo servem de abrigo para a sobrevivência de organismos indesejados.

TABELA 10 - Estimativa da matriz de coeficiente da relação contemporânea para o Brasil

\begin{tabular}{cccc}
\hline \multicolumn{2}{c}{ Influência } & $\begin{array}{c}\text { Coeficiente } \\
\text { estimado }\end{array}$ & p-Valor \\
\hline Do & Sobre & $-0,3422$ & 0,0622 \\
\hline $\begin{array}{c}\text { Consumo de } \\
\text { agrotóxicos }\end{array}$ & Produtividade & & \\
\hline
\end{tabular}

Fonte: Dados gerados na pesquisa

TABELA 11 - Elasticidades ao impulso de 10\% no consumo de agrotóxicos - Brasil

\begin{tabular}{ccc}
\hline Período & $\begin{array}{c}\text { Produtividade } \\
\text { Agrícola (\%) }\end{array}$ & $\begin{array}{c}\text { Consumo de } \\
\text { agrotóxicos (\%) }\end{array}$ \\
\hline 1 & $-3,42$ & 10,00 \\
2 & $-4,95$ & 4,88 \\
3 & $-2,74$ & 6,74 \\
4 & 1,52 & 8,52 \\
5 & 2,50 & 13,98 \\
6 & 3,27 & 13,65 \\
7 & 4,29 & 13,20 \\
8 & 5,76 & 11,68 \\
9 & 5,91 & 12,99 \\
10 & 4,93 & 11,73 \\
\hline
\end{tabular}

Fonte: Dados gerados na pesquisa

A tendência de longo-prazo é o efeito permanente do uso de agrotóxicos. Conforme observado na Tabela 11 não há convergência do choque inicial, ou seja, no 8 o período pós-choque encontra-se uma variação em torno de $10 \%$. Com o uso dos agrotóxicos, observa-se o controle na perda de produtividade, sendo que desde o quarto período não se nota a variação negativa da mesma. Embora, os agrotóxicos sejam insumos que não contribuam para o aumento inicial da produtividade, a sua utilização impede a ocorrência de perdas (variação negativa) da produtividade. 
E com relação ao choque de $10 \%$ na produtividade, contemporaneamente não há variação do consumo de agrotóxicos (Tabela 12), dada a configuração da construção da matriz de relações contemporâneas. No segundo período há uma redução da variação positiva da produtividade agrícola de $10 \%$ para $8,6 \%$, seguido de uma variação de $8,4 \%$.

TABELA 12 - Elasticidades ao impulso de 10\% na produtividade agrícola - Brasil

\begin{tabular}{ccc}
\hline Período & $\begin{array}{c}\text { Produtividade } \\
\text { Agrícola (\%) }\end{array}$ & $\begin{array}{c}\text { Consumo de } \\
\text { agrotóxicos (\%) }\end{array}$ \\
\hline 1 & 10,00 & 0,00 \\
2 & 8,57 & $-12,07$ \\
3 & 8,44 & $-6,52$ \\
4 & 3,47 & $-11,62$ \\
5 & $-3,49$ & $-21,40$ \\
6 & $-4,10$ & $-21,98$ \\
7 & $-7,21$ & $-23,53$ \\
8 & $-10,11$ & $-22,27$ \\
9 & $-10,38$ & $-20,78$ \\
10 & $-10,10$ & $-21,27$ \\
\hline
\end{tabular}

Fonte: Dados gerados na pesquisa

Enquanto a resposta do consumo de agrotóxicos mostra-se negativa no $2^{\circ}$ período pós-choque, com uma variação de $-12,07 \%$. Seguindo para uma variação negativa de até $-23,53 \%$ no sétimo período pós choque. Esse comportamento pode ser explicado pelo ganho da produtividade relacionado à adição de alguma melhoria tecnológica na agropecuária, como, por exemplo, um novo material genético, novas formulações de fertilizantes, entre outros. Tais tecnologias podem ser capazes de resultar em uma planta mais resistente aos danos causados por pragas e doenças, reduzindo o uso de agrotóxicos na agricultura.

No longo-prazo, observa-se um efeito negativo permanente na produtividade, com variação negativa estabilizada em $-10 \%$ frente ao choque inicial de $10 \%$ na própria variável. Essa variação negativa na produtividade agrícola pode ocorrer devido ao grande gasto energético do sistema agrícola ao longo do tempo, fazendo com que reduza a viabilidade do aumento da produção. O que possivelmente reflete no comportamento de longo-prazo do uso de agrotóxicos, por esse apresentar também efeito permanente, com variação em torno de $-20 \%$ (Tabela 12).
A Tabela 13 apresenta a decomposição da variância do erro de previsão do consumo de agrotóxicos no Brasil. Constata-se que aproximadamente $65 \%$ da variação do erro no consumo de agrotóxicos é causado pela variação da produtividade. Isso é observado no sexto período, quando se inicia a estabilização do choque do consumo de agrotóxicos, ou seja, quando há convergência dos valores para um determinado número.

TABELA 13 - Decomposição histórica da variância do erro de previsão para a série do consumo de agrotóxicos utilizados no Brasil

\begin{tabular}{ccc}
\hline Período & $\begin{array}{c}\text { Produtividade } \\
\text { Agrícola (\%) }\end{array}$ & $\begin{array}{c}\text { Consumo de Agrotóxicos } \\
\text { (\%) }\end{array}$ \\
\hline 1 & 0,00 & 100,00 \\
2 & 50,97 & 49,03 \\
3 & 49,56 & 50,44 \\
4 & 54,15 & 45,85 \\
5 & 61,22 & 38,78 \\
6 & 64,18 & 35,82 \\
7 & 66,82 & 33,18 \\
8 & 68,64 & 31,36 \\
\hline
\end{tabular}

Fonte: Dados gerados na pesquisa

Conforme mostrado na Tabela 14, aproximadamente $20 \%$ da variação do erro da produtividade agrícola do Brasil é causada pela variação do uso dos agrotóxicos. Este resultado é alcançado no sétimo período, a partir do qual há a estabilidade da variância do choque inicial.

TABELA 14 - Decomposição histórica da variância do erro de previsão para a série da produtividade agrícola no Brasil

\begin{tabular}{ccc}
\hline Período & $\begin{array}{c}\text { Produtividade } \\
\text { Agrícola (\%) }\end{array}$ & $\begin{array}{c}\text { Consumo de } \\
\text { Agrotóxicos (\%) }\end{array}$ \\
\hline 1 & 88,29 & 11,71 \\
2 & 80,90 & 19,10 \\
3 & 83,19 & 16,81 \\
4 & 83,14 & 16,86 \\
5 & 81,97 & 18,03 \\
6 & 80,05 & 19,95 \\
7 & 78,58 & 21,42 \\
8 & 77,25 & 22,75 \\
\hline
\end{tabular}

Fonte: Dados gerados na pesquisa 
Com a decomposição do erro de previsão observa-se que as duas variáveis (produtividade agrícola e consumo de agrotóxicos) contribuem uma para outra. Sendo que a contribuição do choque dos agrotóxicos para o erro da produtividade é maior do que a própria participação, uma vez que o emprego dos agrotóxicos na agricultura está relacionado ao fato desse impedir a redução da produtividade. Isto é, o uso do agrotóxico depende do quanto as pragas/doenças estão afetando a plantação.

Os resultados dos testes econométricos indicam que a contribuição do choque do consumo de agrotóxicos para o erro da produtividade é menor. Isto condiz com a visão de Vitti, Otto e Ferreira (2015) de que a produtividade das culturas é influenciada por um conjunto de fatores tais como o tipo de solo, o clima, o genótipo da planta, os tipos de plantas invasoras, as doenças e as pragas. E o uso de agrotóxicos é feito para não ocorrer a redução da produtividade da cultura diante do esperado.

\section{CONSIDERAÇÕES FINAIS}

Apesar dos testes de cointegração evidenciarem relações (equilíbrio) de longo-prazo no consumo de agrotóxicos por hectare entre Brasil, Estados Unidos e países da União Europeia no período de 1990 a 2016, vale lembrar que há possíveis diferenças na maneira como os seus agricultores utilizam os agrotóxicos. Dadas as diferenças entre os sistemas educacional, social, político e econômico entre esses países, parcelas dos agricultores podem adotar precauções de segurança quanto à aplicação dos agrotóxicos de modo contrário ao recomendado nos receituários agronômicos. Ao assim procederem, há variações de riscos à saúde humana e ao ecossistema entre os países ao se usarem os mesmos agrotóxicos (Atreya et al., 2011).

A relação entre o consumo de agrotóxicos por área plantada no Brasil com a produtividade das lavouras brasileiras também mostra relação de equilíbrio de longo-prazo, conforme evidenciado pelos testes de cointegração. Uma vez que o uso de agrotóxicos permite a redução de perdas de produção agrícola causadas por pragas e doenças, o que permite à plantação expressar seu potencial produtivo, ou seja, alcançar sua produtividade potencial para o pacote tecnológico utilizado.

Os resultados do modelo SVEC nos indicam que o consumo de agrotóxicos é para manter a produtividade em seu potencial e não necessariamente para aumentá-la. Por exemplo, se houver um aumento de produtividade de $10 \%$ (advindo, por exemplo, da adoção de nova planta geneticamente modificada ou novo sistema agronômico de plantio adensado) não há aumento contemporâneo do consumo de agrotóxicos, e o mesmo diminui nos anos seguintes. Já o aumento de 10\% no consumo de agrotóxicos devido à incidência não prevista de maior intensidade de pragas e doenças não evita a queda contemporânea da produtividade, mas garante o aumento do consumo de agrotóxicos nos anos seguintes.

Uma das limitações do estudo foi a não análise da relação entre a produtividade e o consumo de agrotóxicos para as duas outras regiões consideradas no artigo, EUA e União Europeia, ficando como sugestões para futuros estudos analisar essas relações. Esses futuros trabalhos poderão ter seus resultados comparados aos seus resultados obtidos no presente artigo para o caso brasileiro.

\section{REFERÊNCIAS}

Atreya, K., Sitaula, B. K., Johnsen, F. H., \& Bajracharya, R. M. (2011). Continuing issues in the limitations of pesticide use in developing countries. Journal of Agricultural and Environmental Ethics, 24(1), 49-62.

Bacha, C. J. C. (2018). Economia e Política Agrícola no Brasil. Editora Alínea.

Banco Mundial. (2018). World Development Indicators. Recuperado em 24 de setembro de 2018, de http:// databank.worldbank.org/data/

Bernanke, B. (1986). Alternative explanations of moneyincome correlation. National bureau of economic research. Cambridge.

Brasil. Instituto Brasileiro do Meio Ambiente e dos Recursos Naturais - IBAMA. (2018). Relatórios de Comercialização de Agrotóxicos. 2009 a 2017. Recuperado em 24 de setembro de 2020, de https://www. ibama.gov.br/agrotoxicos/relatorios-de-comercializacaode-agrotoxicos

Brasil. Instituto Brasileiro de Geografia e Estatística - IBGE. (2018). Sistema IBGE de Recuperação Automática: Produção Agrícola Municipal. Recuperado em 24 de setembro de 2020, de https://sidra.ibge.gov. $\mathrm{br} /$ pesquisa/pam

Brasil. Ministério da Agricultura, Pecuária e Abastecimento - MAPA. (2012). Manual de procedimentos para registros de agrotóxicos. Brasília: Autor. 
Böcker, T. G., \& Finger, R. (2017). A meta-analysis on the elasticity of demand for pesticides. Journal of Agricultural Economics, 68(2), 518-533.

Carneiro, F. F. (2015). Dossiê ABRASCO: um alerta sobre os impactos dos agrotóxicos na saúde. EPSJV/Expressão Popular.

Carvalho, M. A. D., \& Silva, C. R. L. D. (2008). Mudanças na pauta das exportações agrícolas brasileiras. Revista de Economia e Sociologia Rural, 46(1), 53-73.

Curzi, D., Luarasi, M., Raimondi, V., \& Olper, A. (2018). The (lack of) international harmonization of EU standards: import and export effects in developed versus developing countries. Applied Economics Letters, 25(21), 1552-1556.

Dasgupta, S., Meisner, C., Wheeler, D., \& Jin, Y. (2002). Agricultural trade, development and toxic risk. World Development, 30(8), 1401-1412.

Dickey, D. A., \& Pantula, S. G. (1987). Determining the order of differencing in autoregressive processes. Journal of Business \& Economic Statistics, 5(4), 455-461.

Ecobichon, D. J. (2001). Pesticide use in developing countries. Toxicology, 160(1-3), 27-33.

Elliott, G., Rothenberg, T. J., \& Stock, J. H. (1996). Efficient tests for an autoregressive unit root. Econometrica, 64(4), 813-836.

Enders, W. (2010). Applied econometric time series (3rd ed.). Wiley.

Engle, R. F., \& Granger, C. W. (1987). Co-integration and error correction: representation, estimation, and testing. Econometrica: journal of the Econometric Society, 251-276.

Food and Agriculture Organization of the United Nations - FAO. (2018). The statistic division - FAOSTAT. Recuperado em 10 se setembro de 2018, de http://www. fao.org/faostat/

Johansen, S. (1988). Statistical analysis of cointegration vectors. Journal of economic dynamics and control, 12(23), 231-254.
Gallo, D., Nakano, O., Silveira Neto, S., Carvalho, R. P. L., Baptista, G.C., Berti Filho, E., Parra, J. R. P., Zucchi, R. A., Alves, S. B., Vendramim, J. D., Marchini, L. C., Lopes, J. R. S., \& Omoto, C. (2002). Métodos de Controle. In: Entomologia Agrícola (Cap. 10, pp. 243-360). Piracicaba: FEALQ.

Hamilton, J. D. (1994). Time Series Analysis. New Jersey: Princeton University Press.

Lopes, C. V. A., \& Albuquerque, G. S. C. D. (2018). Agrotóxicos e seus impactos na saúde humana e ambiental: uma revisão sistemática. Saúde em debate, 42, 518-534.

MacKinnon, J. G. (1996). Numerical distribution functions for unit root and cointegration tests. Journal of applied econometrics, 11(6), 601-618.

Pfaff, B. (2008). VAR, SVAR and SVEC models: Implementation within $\mathrm{R}$ package vars. Journal of Statistical Software, 27(4), 1-32.

Pedlowski, M. A., Canela, M. C., da Costa Terra, M. A., \& de Faria, R. M. R. (2012). Modes of pesticides utilization by Brazilian smallholders and their implications for human health and the environment. Crop Protection, 31(1), 113-118.

Reis, E. M., Casa, R. T., \& Bianchin, V. (2011). Controle de doenças de plantas pela rotação de culturas. Summa Phytopathologica, 37(3), 85-91.

Schreinemachers, P., \& Tipraqsa, P. (2012). Agricultural pesticides and land use intensification in high, middle and low income countries. Food policy, 37(6), 616-626.

Sims, C. Are forecasting models usable for policy analysis? Quarterly review-Federal Reserve Bank of Minneapolis. 1986.

Souza, P. M. D., \& Lima, J. E. D. (2003). Intensidade e dinâmica da modernização agrícola no Brasil e nas unidades da Federação. Revista Brasileira de Economia, 57(4), 795-824.

Vitti, G. C., Otto, R., \& Ferreira, L. R. P. (2015). Nutrição e adubação da cana-de-açúcar: manejo nutricional da cultura da cana-de-açúcar. In Processos agrícolas e mecanização da cana-de-açúcar. Jaboticabal.

Williams, S. P., \& Shumway, C. R. (2000). Trade liberalization and agricultural chemical use: United States and Mexico. American Journal of Agricultural Economics, 82(1), 183-199. 


\section{ANEXO}

TABELA 15 - Alguns indicadores estatísticos do ajustamento do modelo VEC quanto a relação entre consumo de agrotóxicos no Brasil, nos Estados Unidos e União Europeia (testes de diagnóstico)

\begin{tabular}{cccccc}
\hline Diagnóstico & Teste & Estatística & $\begin{array}{c}\text { Distribuição } \\
\text { aproximada }\end{array}$ & p-valor & Conclusão \\
\hline Normalidade & JB & 2,757 & $(4)$ & 0,839 & Não rejeita H0: Resíduos com distribuição normal \\
Autocorrelação & PT.adjusted-15 & 124,550 & $(111)$ & 0,179 & Não rejeita H0: Ausência de autocorrelação \\
Autocorrelação & PT.adjusted-18 & 143,34 & $(138)$ & 0,360 & Não rejeita H0: Ausência de autocorrelação \\
Autocorrelação & PT.adjusted-20 & 153,17 & $(156)$ & 0,549 & Não rejeita H0: Ausência de autocorrelação \\
Autocorrelação & ES-1 & 0,698 & F $(9-22)$ & 0,704 & Não rejeita H0: Ausência de autocorrelação \\
Autocorrelação & ES-2 & 1,023 & F $(18-17)$ & 0,483 & Não rejeita H0: Ausência de autocorrelação \\
\hline
\end{tabular}

Nota: JB = teste de Jaque-Bera; PT adjusted- $n=$ Teste de Portmanteau ajustado para amostras pequenas; ES = Teste de EdgertonShukur; $\mathrm{n}=$ número de defasagem

Fonte: Dados gerados na pesquisa

TABELA 16 - Alguns indicadores estatísticos do ajustamento do modelo SVEC quanto a relação entre produtividade agrícola e consumo de agrotóxicos no Brasil (testes de diagnóstico)

\begin{tabular}{cccccc}
\hline Diagnóstico & Teste & Estatística & $\begin{array}{c}\text { Distribuição } \\
\text { aproximada }\end{array}$ & p-valor & Conclusão \\
\hline Normalidade & JB & 2,829 & $\chi^{2}(4)$ & 0,587 & Não rejeita H0: Resíduos com distribuição normal \\
Autocorrelação & PT.adjusted-15 & 41,739 & $\chi^{2}(34)$ & 0,170 & Não rejeita H0: Ausência de autocorrelação \\
Autocorrelação & PT.adjusted-18 & 52,31 & $\chi^{2}(46)$ & 0,242 & Não rejeita H0: Ausência de autocorrelação \\
Autocorrelação & PT.adjusted-20 & 59,158 & $\chi^{2}(58)$ & 0,433 & Não rejeita H0: Ausência de autocorrelação \\
Autocorrelação & ES-1 & 1,129 & F $(4-22)$ & 0,368 & Não rejeita H0: Ausência de autocorrelação \\
Autocorrelação & ES-2 & 0,581 & F $(8-18)$ & 0,781 & Não rejeita H0: Ausência de autocorrelação \\
\hline
\end{tabular}

Nota: JB = teste de Jaque-Bera; PT adjusted- $\mathrm{n}=$ Teste de Portmanteau ajustado para amostras pequenas; ES = Teste de EdgertonShukur; $\mathrm{n}=$ número de defasagem.

Fonte: Dados gerados na pesquisa 


\section{APÊNDICE}

TABELA 17 - Evolução da produtividade das lavouras e do consumo de agrotóxicos por hectare no Brasil

\begin{tabular}{|c|c|c|}
\hline Ano & $\begin{array}{c}\text { Produtividade para } 38 \text { culturas } \\
(\mathrm{Kg} / \mathrm{ha})\end{array}$ & Quantidade de agrotóxicos por área $(\mathrm{Kg} / \mathrm{ha})$ \\
\hline 1990 & 7.618 & 0,2057 \\
\hline 1991 & 7.610 & 0,2382 \\
\hline 1992 & 8.022 & 0,2716 \\
\hline 1993 & 8.164 & 0,3033 \\
\hline 1994 & 8.515 & 0,3353 \\
\hline 1995 & 8.990 & 0,3597 \\
\hline 1996 & 9.918 & 0,3923 \\
\hline 1997 & 10.066 & 0,4248 \\
\hline 1998 & 10.528 & 0,4572 \\
\hline 1999 & 10.058 & 0,4893 \\
\hline 2000 & 9.734 & 0,5372 \\
\hline 2001 & 10.387 & 0,5751 \\
\hline 2002 & 10.248 & 0,5475 \\
\hline 2003 & 10.419 & 0,6796 \\
\hline 2004 & 9.981 & 0,7890 \\
\hline 2005 & 9.942 & 0,8524 \\
\hline 2006 & 11.187 & 0,8751 \\
\hline 2007 & 12.641 & 1,1193 \\
\hline 2008 & 13.810 & 1,1431 \\
\hline 2009 & 14.291 & 1,2274 \\
\hline 2010 & 14.985 & 1,2527 \\
\hline 2011 & 14.828 & 1,2529 \\
\hline 2012 & 14.566 & 1,2575 \\
\hline 2013 & 14.733 & 1,3156 \\
\hline 2014 & 13.592 & 1,2425 \\
\hline 2015 & 13.883 & 1,3927 \\
\hline 2016 & 13.864 & 1,3302 \\
\hline
\end{tabular}

Fonte: IBGE e FAOSTAT. Dados processados pelos autores 
TABELA 18 - Evolução do consumo de agrotóxicos por hectare de lavouras nos EUA, Brasil e União Europeia

\begin{tabular}{|c|c|c|c|}
\hline \multirow{2}{*}{ Ano } & \multicolumn{3}{|c|}{ Quantidade de agrotóxicos/Área (t/mil ha) } \\
\hline & Brasil & Estados Unidos & União Europeia \\
\hline 1990 & 0,2057 & 0,9392 & 2,0591 \\
\hline 1991 & 0,2382 & 0,9009 & 1,9994 \\
\hline 1992 & 0,2716 & 0,9425 & 1,7571 \\
\hline 1993 & 0,3033 & 0,9266 & 1,8470 \\
\hline 1994 & 0,3353 & 1,0114 & 1,7918 \\
\hline 1995 & 0,3597 & 1,0073 & 1,8108 \\
\hline 1996 & 0,3923 & 1,0405 & 1,8418 \\
\hline 1997 & 0,4248 & 1,0474 & 1,9480 \\
\hline 1998 & 0,4572 & 1,0241 & 1,9756 \\
\hline 1999 & 0,4893 & 1,0477 & 1,9425 \\
\hline 2000 & 0,5372 & 1,0377 & 1,8836 \\
\hline 2001 & 0,5751 & 0,9915 & 1,8794 \\
\hline 2002 & 0,5475 & 1,0092 & 1,9693 \\
\hline 2003 & 0,6796 & 1,0093 & 1,8879 \\
\hline 2004 & 0,7890 & 1,0328 & 1,9457 \\
\hline 2005 & 0,8524 & 0,9429 & 1,9848 \\
\hline 2006 & 0,8751 & 0,9599 & 1,8434 \\
\hline 2007 & 1,1193 & 0,9690 & 1,9560 \\
\hline 2008 & 1,1431 & 0,9175 & 1,9792 \\
\hline 2009 & 1,2274 & 0,8741 & 1,7564 \\
\hline 2010 & 1,2527 & 0,9177 & 1,7611 \\
\hline 2011 & 1,2529 & 0,9670 & 1,8858 \\
\hline 2012 & 1,2575 & 0,9977 & 1,8541 \\
\hline 2013 & 1,3156 & 1,0048 & 1,8306 \\
\hline 2014 & 1,2425 & 0,9998 & 1,9920 \\
\hline 2015 & 1,3927 & 1,0047 & 1,9610 \\
\hline 2016 & 1,3302 & 1,0047 & 1,9993 \\
\hline
\end{tabular}

Fonte: FAOSTAT. Dados processados pelos autores 